\title{
Analysis of CFRP Laminates Properties under Different Layup Structure using Finite Element Analysis
}

\author{
Xinye Liu ${ }^{1, a,{ }^{*}}$, Jinhui Cai ${ }^{1, b}$, Jiusun Zeng ${ }^{1, c}$, Fang Ye ${ }^{1, d}$, Wing Chiu ${ }^{2, e}$ \\ ${ }^{1}$ College of Metrology and Measurement Engineering, China Jiliang University, Hangzhou \\ 310018, China \\ ${ }^{2}$ Department of Mechanical and Aerospace Engineering, Monash University, Melbourne, 3800, \\ Australia \\ a p1802085239@cjlu.edu.cn; b caijinhui@cjlu.edu.cn; cjszeng@cjlu.edu.cn; \\ d18a0205108@cjlu.edu.cn; e wing.kong.chiu@monash.edu
}

\section{Keywords: Laminate, Finite Element Analysis, Laying Angle, Stacking Sequences}

\begin{abstract}
In order to study the effect of the layup structure on the static strength and low-velocity impact strength of carbon fiber/epoxy composite (CFRP) laminates, theoretical simulation analysis under different laying angles have been carried out. In this study, Finite Element Analysis (FEA) models for different CFRP laminate specimens are created using ANSYS Workbench by changing the relative volume fraction of $0^{\circ}, 45^{\circ}$ and $90^{\circ}$ plies in each specimen and their relative location. The FEA results revealed that the increase of relative volume of $90^{\circ}$ ply will improve the impact the impact resistance performance, while the increase of relative volume of $45^{\circ}$ ply will take the opposite effect. Moreover, when the relative volume fraction of $0^{\circ}, 45^{\circ}$ and $90^{\circ}$ plies are the same, the strength performance of the laminate cannot be improved by changing the thickness of the outermost layer. The study illustrated the significant effects of different stacking sequences and laying angles on the tensile and flexural failure mechanisms in composite laminates, leading to some suggestions to improve the design of composite laminates.
\end{abstract}

\section{Introduction}

Carbon fiber reinforced composite laminate is made of a series of unidirectional carbon fiber reinforced resin-based materials. It has the characteristics of heterogeneity, anisotropy, high intra-layer strength and high comprehensive strength, and has been widely used in military, aerospace and other fields[1,2]. However, this type of laminate has the disadvantages of low interlayer and vertical layer strength, so that the impact of runway gravel, hail and other objects on the composite laminate can easily cause its failure in the service environment[3]. Nowadays, laying angles between layers are mostly standard angles of $0^{\circ}, \pm 45^{\circ}$ and $90^{\circ}$. The performance of the laminate varies depending on the position of the laying angles. Therefore, the effect of the stacking angles and the stacking sequences on the performance of the laminate is studied[4].

Meng et al.[5] studied the effect of fiber layup on the bending failure of composite laminates by means of 3D finite element analysis. Kannan et al.[6] evaluated the tensile strength of 2D Carbon/Carbon laminates with a center-hole based on the FEA. However, Guo et al.[7] found that the distribution of interlayer stress around the void is related to the layer structure. In addition, the choice of failure criterion has an impact on the FEA of laminates, Naik et al.[8] proposed the minimum weight design of composite laminates using the failure mechanism based, maximum stress and Tsai-Wu failure criteria. And Akbulut et al.[9] proposed an optimization procedure to minimize thickness of laminated composite plates subject to in-plane loading, fiber orientation angles and layer thickness are chosen as design variables. On the other hands, Liu et al.[10] 
explore the effects of different failure criterion including Puck, Hashin and Chang-Chang criterion on the dynamic progressive failure properties of carbon fiber composite laminates.

In this paper, the 3D model of CFRP laminates is established through ANSYS Workbench, static structure analysis and explicit dynamics analysis are performed on laminates of different layup structures to study the effect of lay angle and lay sequence on static strength and impact resistance of laminates influences. Then determine the failure criteria of the laminate and analyze its critical failure layer, which provides a theoretical basis for improving the performance of the composite laminate by optimizing the layer structure.

\section{Experiments}

Theoretical Model of Laminates. Establishing 3D FEA models of composite laminates with different stacking sequences in ANSYS Workbench, as shown in Table 1. The size of the specimen is $250 \mathrm{~mm} * 36 \mathrm{~mm} * 2 \mathrm{~mm}$, a total of 16 layers and a single layer thickness of $0.125 \mathrm{~mm}$. The composite laminates considered in this paper are made of carbon/epoxy prepreg and has a symmetrical structure. The mechanical properties of each lamina are shown in Table 2.

Table 1 Different lay-ups of the composite laminates

\begin{tabular}{cccc}
\hline Specimen Number & Stacking Sequences & Specimen Number & Stacking Sequences \\
\hline Laminate & {$\left[0_{8}\right]_{\mathrm{s}}$} & Laminate 5 & {$\left[90 / 0 / 90 / 0 / 90_{4}\right]_{\mathrm{s}}$} \\
Laminate2 & {$\left[0 / 90 / 0 / 90 / 0_{4}\right]_{\mathrm{s}}$} & Laminate6 & {$\left[+45 / 0 /-45 / 0 / \pm 45_{2}\right]_{\mathrm{s}}$} \\
Laminate3 & {$\left[0 /+45 / 0 /-45 / 0_{4}\right]_{\mathrm{s}}$} & Laminate7 & {$\left[90 / 90 / 0 / 0 / 90_{4}\right]_{\mathrm{s}}$} \\
Laminate4 & {$[0 /+45 / 90 /-45]_{2 \mathrm{~s}}$} & Laminate8 & {$\left[+45 /-45 / 0 / 0 / \pm 45_{2}\right]_{\mathrm{s}}$} \\
\hline
\end{tabular}

Notes: The numeric subscripts indicate the number of layers stacked in each direction and the subscript [ $\cdot$. - ] s indicates that plies are symmetric about the midplane of the laminate.

Table 2 The mechanical properties of each laminate

\begin{tabular}{ccccc}
\hline$\rho / \mathrm{kg} \cdot \mathrm{m}^{-3}$ & $\mathrm{E}_{1} / \mathrm{GPa}$ & $\mathrm{E}_{2} / \mathrm{GPa}$ & $\mathrm{E}_{3} / \mathrm{GPa}$ & $\mathrm{G}_{12} / \mathrm{GPa}$ \\
\hline 1490 & 121 & 8.6 & 8.6 & 4.7 \\
\hline $\mathrm{G}_{13} / \mathrm{GPa}$ & $\mathrm{G}_{23} / \mathrm{GPa}$ & $\mu_{12}$ & $\mu_{13}$ & $\mu_{23}$ \\
\hline 4.7 & 3.1 & 0.27 & 0.27 & 0.4 \\
\hline
\end{tabular}

In the low-velocity impact simulation, a cone bullet with a length to diameter ratio of 3:1 is used to impact the laminate. The bullet is made of structural steel. Its mass, density, elastic modulus and Poisson's ratio are $6.2 \mathrm{~g}, 7850 \mathrm{~kg} \cdot \mathrm{m}^{-3}, 200 \mathrm{GPa}$ and 0.3 respectively.

Meshing and Constrained Boundary Conditions. Since the meshing structure and the degree of density will directly affect the accuracy of the results and the calculation time in ANSYS Workbench, the direct meshing method is selected according to the geometric characteristic of the 3D model of the composite laminate and the force characteristic. After the mesh is divided, referring to its skewness and orthogonal quality parameter, it is found that the optimal mesh sizes for laminates and bullets are $3 \mathrm{~mm}$ and $2 \mathrm{~mm}$, respectively.

In the FEA, the static structural analysis and the explicit dynamic analysis are used. When the static structural module is used for analysis, the two short sides of the composite laminate are constrained and fixed, as shown in Fig. 1, the force is $2500 \mathrm{~N}$. While the four sides of the composite laminate are fully constrained when the explicit dynamics module is used for analysis, and the displacement and rotation angle in the three directions are all zero, that is, completely fixed. In 
addition, the angular velocity and velocity of the bullet in other directions are constrained to zero in order to better extract the experimental results. Define the initial velocity of the bullet along the coordinate axis $\mathrm{Z}$ in the predefined field, and then define the output stress, strain, displacement and velocity in the field. The assembly diagram for the bullet impacting composite laminates is shown in Fig. 2. After the model is built, define the Tsai-Wu failure criterion and the maximum stress failure criterion in the ACP (Post) module to identify the main failure layers of the composite laminate, and view the stress and strain of each layer. The distance between the bullet and the laminate is $5 \mathrm{~mm}$, and the total movement time is $0.1 \mathrm{~ms}$.

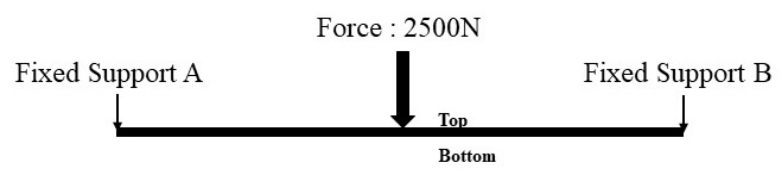

Fig. 1 Schematic graph of the static structural model



Fig. 2 Assembly diagram for the bullet impacting composite laminated plates

\section{Analysis}

When the 3D model of the laminate is established, the total deformation value of each laminate can be obtained as shown in Table 3. We use laminate 1 as a reference to study the performance of laminates with different layer structure through static structural analysis and explicit dynamic analysis.

Table 3 The total deformation value of each laminate

\begin{tabular}{cccc}
\hline Specimen Number & Total deformation value $(\mathrm{mm})$ & Specimen Number & Total deformation value $(\mathrm{mm})$ \\
\hline Laminate1 & 74.754 & Laminate5 & 84.975 \\
Laminate2 & 53.225 & Laminate6 & 71.809 \\
Laminate3 & 50.055 & Laminate7 & 100.94 \\
Laminate4 & 68.303 & Laminate8 & 80.829 \\
\hline
\end{tabular}

Effect of Stacking Angle on Laminate Performance. Laminate1 only contains $0^{\circ}$ plies and its total deformation is $74.754 \mathrm{~mm}$. Laminate 2 is a part of $0^{\circ}$ plies in laminate 1 replaced with $90^{\circ}$ plies, and its total deformation is reduced to $53.225 \mathrm{~mm}$. For laminate 3 , the $90^{\circ}$ plies in laminate 2 is replaced with $45^{\circ}$ plies, and its total deformation is reduced to $50.055 \mathrm{~mm}$. If the laminate contains three ply angles at the same time such as laminate4, its total deformation is better than laminate1, but inferior to laminate 2 and laminate 3 . From this we see that adding $45^{\circ}$ plies to the laminate 1 with only $0^{\circ}$ plies show better bending resistance.

In the explicit dynamic analysis module, set the bullet velocity to $80 \mathrm{~m} / \mathrm{s}$ and the maximum equivalent stresses of laminate1 to lanimate4 are $190.71 \mathrm{MPa}, 391.55 \mathrm{MPa}, 82.849 \mathrm{MPa}$ and 94.776 MPa respectively, as shown in Fig. 3. From the laminate 3 and laminate4, which can be seen that the equivalent stress of the $45^{\circ}$ laminate between adjacent layers is smaller and the impact 
resistance is stronger. Moreover, the curve of these two types of laminates are smoother under the continuous impact.

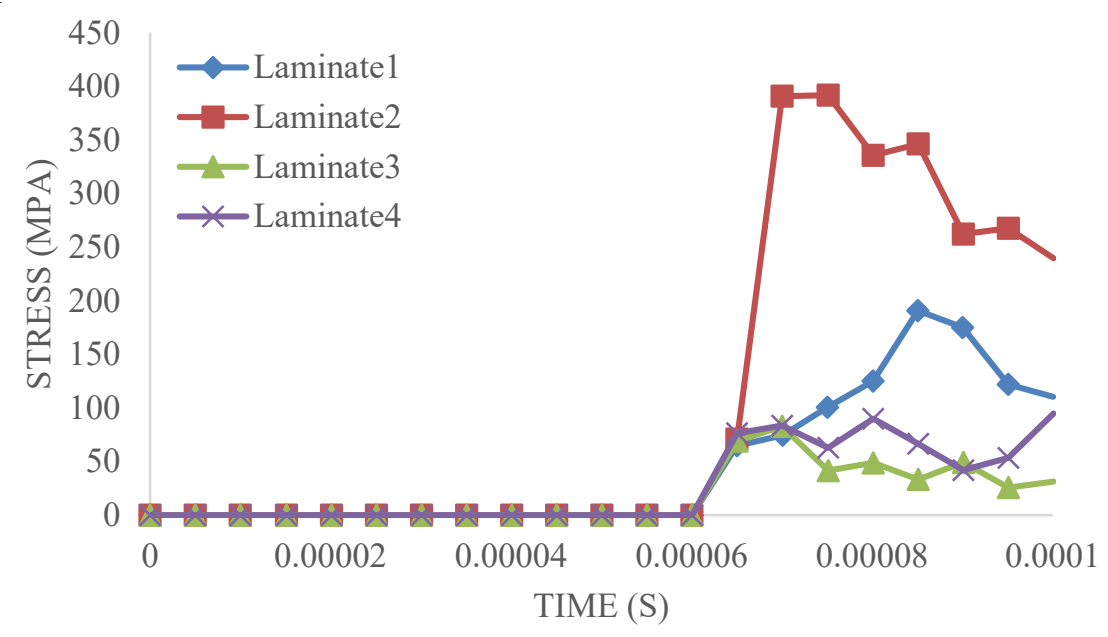

Fig. 3 Equivalent stress curve of laminate1 to laminate 4

Effect of Stacking Sequence on Laminate Performance. Laminate2, laminate5 and laminate7 contain the same layer angle, but the stacking sequence has changed. Compared with laminate2, the relative volume fraction of $0^{\circ}$ and $90^{\circ}$ plies of the laminate 5 is changed, and the fiber direction of the outermost layer is also changed. The total deformation of laminate 2 is less than the total deformation of laminate5, which has better bending resistance. When changing the thickness of the outermost layer, but the relative volume fraction of $0^{\circ}$ and $90^{\circ}$ plies remains unchanged, such as laminate 5 and laminate 7 . The total deformation of laminate 7 is $100.94 \mathrm{~mm}$, which is more than laminate 5. However, analyze laminate 3 , laminate 6 and laminate 8 in the same way, and they have the same layer angle. Laminate 3 has the strongest bending resistance, followed by laminate6, while laminate 8 is the worst. The larger the relative volume of $0^{\circ}$, the stronger the performance of the bending strength. And the bending resistance of the laminate cannot be improved by changing the thickness of the outermost layer.

In the explicit dynamic analysis module, set the bullet velocity to $80 \mathrm{~m} / \mathrm{s}$ and the equivalent stresses curve is shown in the Fig. 4 and Fig. 5. The relative volume fraction of $0^{\circ}$ and $90^{\circ}$ plies are different, such as laminate 2 and laminate 5 . And the relative volume fraction of $0^{\circ}$ and $45^{\circ}$ plies are different, such as laminate 3 and laminate6. Comparing the two types of laminates, it can be found that an increase in the relative volume of $90^{\circ}$ ply will improve the impact the impact resistance performance, while an increase in the relative volume of $45^{\circ}$ ply will be the opposite. However, when the thickness of the outermost layer of the laminate is increased, the equivalent stress of the laminate is basically not affected.

When the failure mode is set to the Tsai-Wu and the maximum stress failure criterion to observe the main failure modes and layer of each laminate, which can be found that the main failure mode of the laminate1 is the maximum stress failure. While the others are the Tsai-Wu failure mode. Moreover, the $90^{\circ}$ ply is more prone to failure, as long as the laminate contains $90^{\circ}$ ply, which determines the service life of the laminate. And it can be seen from the Fig. 6 that the damage range of the laminate model with $90^{\circ}$ ply will be larger and the stress is more dispersed. On the contrary, the stresses of the laminate containing $0^{\circ}$ and $45^{\circ}$ plies are mainly concentrated in the center of the model. 


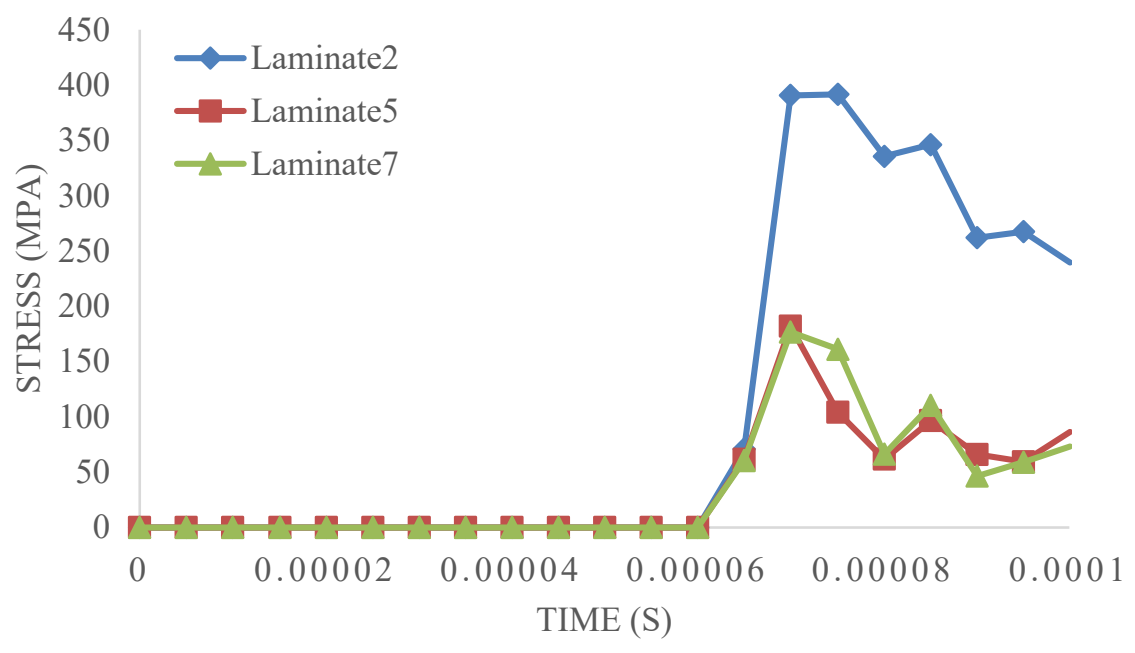

Fig. 4 Equivalent stress curve of laminate2, laminate5 and laminate 7

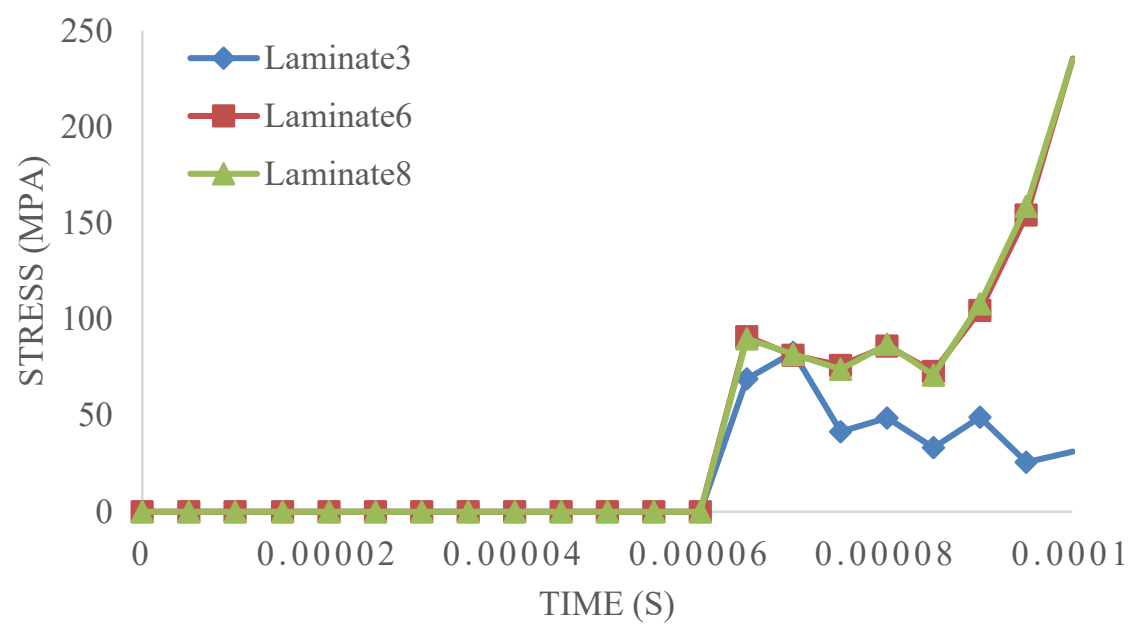

Fig. 5 Equivalent stress curve of laminate3, laminate6 and laminate8

(a)

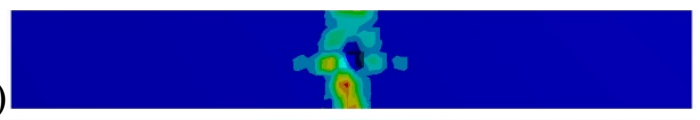

(c)

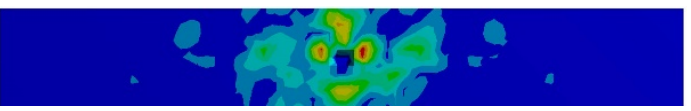

(e)

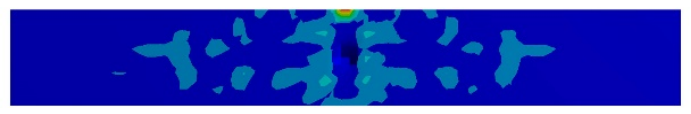

(g)

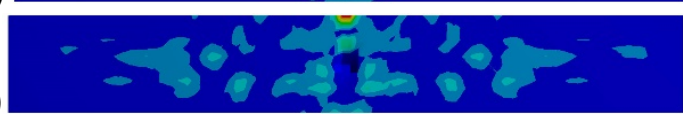

(b)

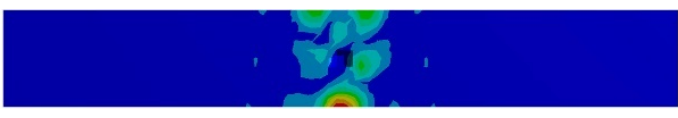

(d)

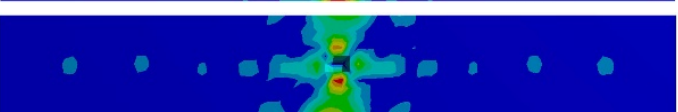

(f)

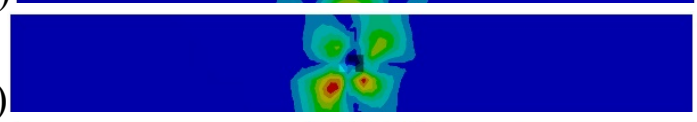

(h)

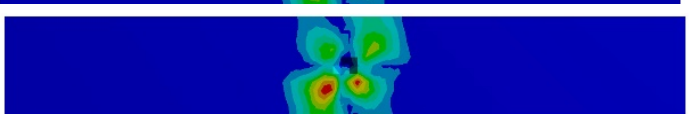

Fig. 6 Equivalent stress diagram of each laminate: (a)laminate1; (b)laminate2; (c)laminate3; (d)laminate4; (e)laminate 5; (f)laminate6; (g)laminate 7; (h)laminate8

\section{Conclusion}

According to the FEA results, the following conclusion can be drawn. (1) The laminate with only $0^{\circ}$ and $45^{\circ}$ plies and has a higher relative volume of $0^{\circ}$ ply, which has the stronger bending 
resistance performance. (2) It is found that when the relative volume fraction of $0^{\circ}, 45^{\circ}$ and $90^{\circ}$ plies are the same, the strength performance of the laminate cannot be improved by changing the thickness of the outermost layer from the static structure analysis and explicit dynamic analysis. And in all laminate models, the $90^{\circ}$ layer is the key layer that is more prone to failure, while the probability of failure at $0^{\circ}$ and $45^{\circ}$ is basically the same. (3) The laminate with only two types of layer angles, either $0^{\circ}$ and $90^{\circ}$, or $0^{\circ}$ and $45^{\circ}$. The results show that the increase of relative volume of $90^{\circ}$ ply will improve the impact the impact resistance performance, while the increase of relative volume of $45^{\circ}$ ply will be the opposite. Layer angle and layer sequence have an impact on the bending resistance and impact resistance of the laminate.

\section{References}

[1] Liu, DeFu, YongJun Tang, and W. L. Cong. "A review of mechanical drilling for composite laminates." Composite structures 94.4 (2012): 1265-1279. https://doi.org/10.1016/j.compstruct.2011.11.024

[2] Zhang, Y. X., and C. H. Yang. "Recent developments in finite element analysis for laminated composite plates." Composite structures 88.1 (2009): 147-157.

https://doi.org/10.1016/j.compstruct.2008.02.014

[3] De Baere, Ives, Wim Van Paepegem, and Joris Degrieck. "Comparison of different setups for fatigue testing of thin composite laminates in bending." International Journal of Fatigue 31.6 (2009): 1095-1101. https://doi.org/10.1016/j.ijfatigue.2008.05.011

[4] Kashtalyan, Maria, and Costas Soutis. "Analysis of local delaminations in composite laminates with angle-ply matrix cracks." International Journal of Solids and Structures 39.6 (2002): 1515-1537. https://doi.org/10.1016/S0020-7683(02)00007-0

[5] Meng, Maozhou, et al. "3D FEA modelling of laminated composites in bending and their failure mechanisms." Composite Structures 119 (2015): 693-708.

https://doi.org/10.1016/j.compstruct.2014.09.048

[6] Kannan, V. Kamala, et al. "Finite element analysis and notched tensile strength evaluation of center-hole 2D carbon/carbon laminates." Advanced Composite Materials 20.3 (2011): 289-300. https://doi.org/10.1163/092430410X550854

[7] Guo, Zhangxin, Xiaoping Han, and Xiping Zhu. "Finite element analysis of interlaminar stresses for composite laminates stitched around a circular hole." Applied Composite Materials 19.3-4 (2012): 561-571. https://doi.org/10.1007/s10443-011-9234-7

[8] Naik, G. Narayana, S. Gopalakrishnan, and Ranjan Ganguli. "Design optimization of composites using genetic algorithms and failure mechanism based failure criterion." Composite Structures 83.4 (2008): 354-367. https://doi.org/10.1016/j.compstruct.2007.05.005

[9] Akbulut, Mustafa, and Fazil O. Sonmez. "Optimum design of composite laminates for minimum thickness." Computers \& Structures 86.21-22 (2008): 1974-1982.

https://doi.org/10.1016/j.compstruc.2008.05.003

[10] Liu, P. F., et al. "Finite element analysis of dynamic progressive failure of carbon fiber composite laminates under low velocity impact." Composite Structures 149 (2016): 408-422. https://doi.org/10.1016/j.compstruct.2016.04.012 